\title{
Simulation and Analysis for Sustainability in Manufacturing Processes
}

Alexander P. Muroyama Mahesh Mani Kevin Lyons Bjorn Johansson 


\title{
Simulation and Analysis for Sustainability in Manufacturing Processes
}

\author{
Alexander P. Muroyama \\ Mechanical Engineering Department \\ University of Maryland, College Park \\ Mahesh Mani \\ Kevin Lyons \\ Manufacturing Systems Integration Division \\ Engineering Laboratory \\ Bjorn Johansson \\ Product and Production Development \\ Chalmers University of Technology
}

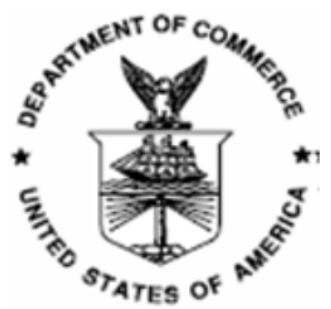

U.S. Department of Commerce Gary Locke, Secretary National Institute of Standards and Technology Pat Gallagher, Director 


\section{Table of Contents}

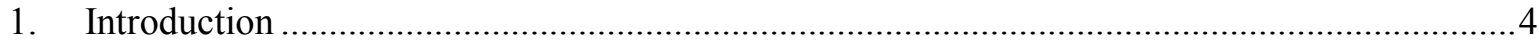

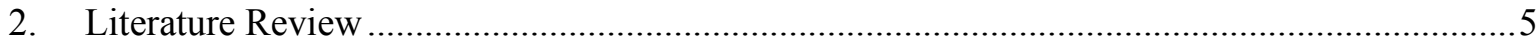

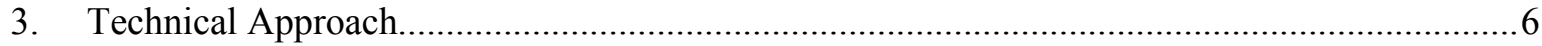

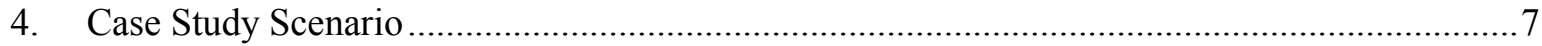

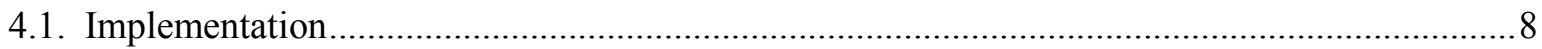

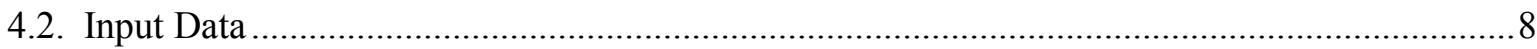

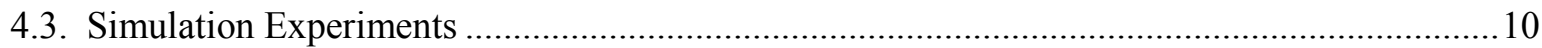

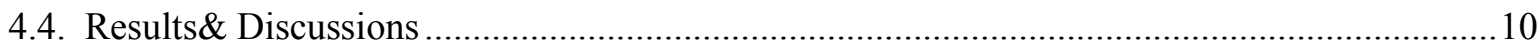

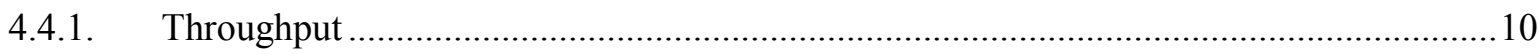

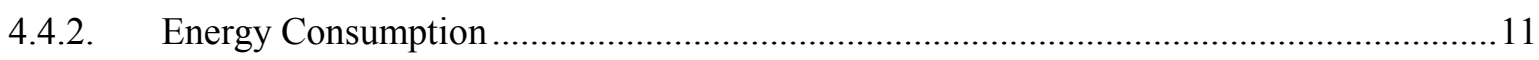

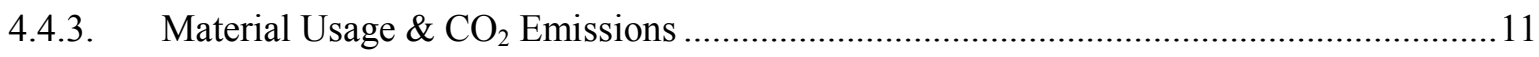

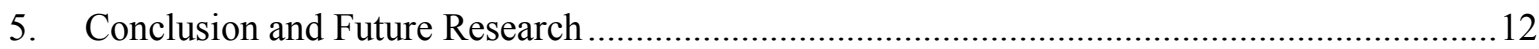

6. Acknowledgments .............................................................. Error! Bookmark not defined.

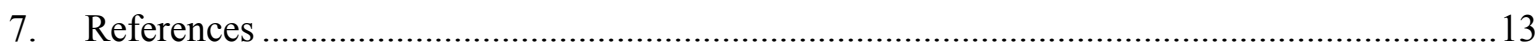

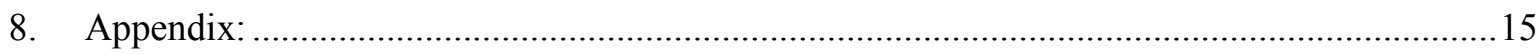

\section{List of Figures}

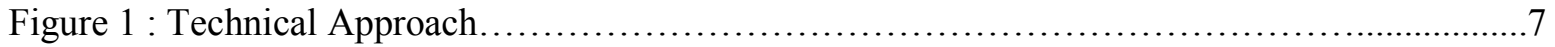

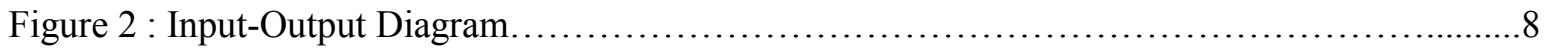

Figure 3 : AutoMod Factory Layout (1 Injection Molding Machine) .........................8

Figure 4 : AutoMod Factory Layout (2 Injection Molding Machines)............................

Figure 5 : Weekly Throughput...............................................................

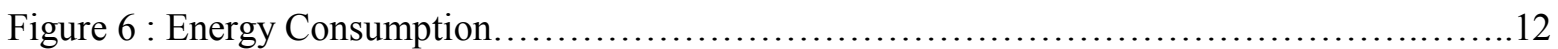

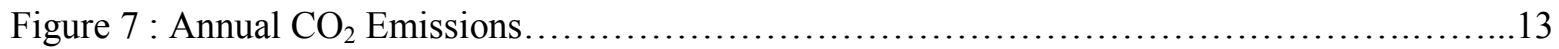

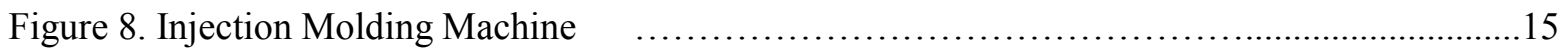

Figure 9. Injection molding of Golf balls........................................... 15

Figure 9. Runtime snapshot from AutoMod with one injection molding machine................16

Figure 10. Runtime snapshot from AutoMod with two injection molding machines...................16

\section{List of Tables}

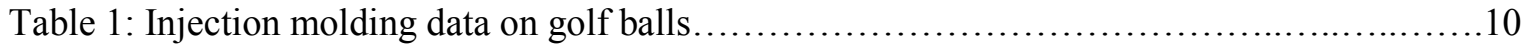

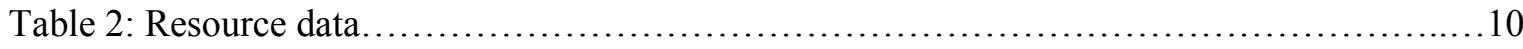

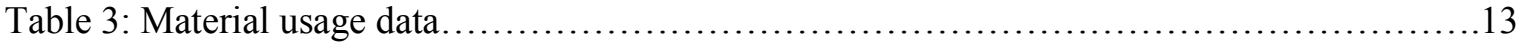




\title{
Simulation and Analysis for Sustainability in Manufacturing Processes
}

\begin{abstract}
:
Sustainability has become a u biquitous term in almost every field, especially in engineering design and manufacturing. Recently, an increased awareness of environmental problems and resource depletion has led to an emphasis on environmentally friendly practices. This is especially true in the manufacturing industry where energy consumption and the amount of waste generated can be high. This requires proactive tools to be developed to carefully analyze the cause-effect of current manufacturing practices and to investigate alternative practices. One such approach to sustainable manufacturing is the combined use of Discrete Event Simulation (DES) and Life Cycle Assessment (LCA) to analyze the utilization and processing of manufacturing resources in a f actory setting. On an economic aspect such method can significantly reduce the financial and environmental costs by evaluating the system performance before its construction or use. This project considers what-if scenarios in a simplified golf ball factory, using as close to real-world data as possible, to demonstrate DES and LCA's ability to facilitate decision-making and optimize the manufacturing process. Plastic injection molding, an energy-intensive step in the golf ball manufacturing process, is the focus of the DES model. AutoMod, a 3-D modeling software, was used to build the DES model and AutoStat was used to run the trials and analyze the data. By varying the input parameters such as type and number of injection molding machines and material used, the simulation model can output data indicating the most productive and energy efficient methods. On a more detailed level, the simulations can provide valuable information on bottlenecks or imbalances in the system. Correcting these can allow the factory to be both "greener" and more cost-effective. This study illustrates a small but important aspect of the supply chain thus demonstrating the systems approach to sustainability.
\end{abstract}

Keywords: Sustainability, Discrete Event Simulation, Life Cycle Assessment, Injection Molding

\section{Introduction}

For many manufacturing companies, the term sustainability has become synonymous with not only the preservation of the environment, but importantly cost-savings and efficiency. Discrete Event Simulation (DES) is a powerful computing technique for understanding the behavior of systems. A system is a collection of entities (e.g., people and machines) that interact over time. In a factory setting, DES software can be a vital tool in analyzing the efficiency. Through the consideration of what-if scenarios, conclusions can be drawn on how to optimize a system's performance before its construction or use. Although DES is widely implemented as an analysis and problem-solving tool in factory designs, only recently has environmental sustainability been considered in conjunction with DES. Life Cycle Assessment (LCA) is an evaluation of a product's environmental impact during its life cycle. Life Cycle Inventory (LCI) as part of LCA involves the data collection, modeling, description and verification of data. The LCI database in general encompasses all relevant data that help quantify the material and energy flows into and 
out of the environment for relevant unit processes within study boundaries. When LCA is implemented along with DES, environmentally friendly decisions can be made that reduce a manufacturing system's environmental impact to society.

Injection molding is one of the most common manufacturing processes in use today. About a third of all plastics by weight are processed through injection molding [1]. The process, which entails melting a polymer resin in a barrel and injecting it into a clamped mold, is very energyintensive (See Appendix Figure 8). In addition, the plastics themselves present environmental challenges: they are slow to break down in landfills and can release harmful substances during use or disposal [2]. At the same time, injection molding provides a straightforward and highly automated method of producing large quantities of products. Injection molding is one method of manufacturing two-piece golf balls. About a billion golf balls are produced each year, and like many manufacturing processes, it takes a significant amount of energy and materials. For this reason, a simplified golf ball factory is the focus of our case study.

\section{Literature Review}

The applications of DES are not limited to manufacturing systems design. Simulation in general can be used to evaluate efficiency and profitability in any queuing system, such as hospitals or airports. Additionally, 3-D modeling and simulation software are rapidly evolving and becoming more capable every year. Today, environmental responsibility is becoming increasingly relevant with growing concerns about pollution, resource depletion, global warming, and energy. One approach to improving sustainability in manufacturing is combining DES and LCA to analyze how changing various parameters affects the waste materials and energy used by the system along with the throughput. Few research publications in this area exist, but the area has gained popularity in the recent years

Earlier Solding and Thollander [3] describe how DES could be utilized to reduce electricity consumption for foundries. Östergren et al. [4] and Johansson et al. [5] describe how DES could be utilized in combination with LCA for decreasing environmental impacts during food production. More recently Johansson et al. [6] used a model of a paint shop to demonstrate planning a manufacturing setup with an emphasis on sustainability. As far as injection molding goes, 3-D modeling has been used to analyze mold designs for efficiency, but has not been used to model the process at a systems level [7].

The energy implications of plastic injection molding have been the focus of several papers. More specifically, the three types of injection molding machine: all-electric, hydraulic, and hybrid have very different power requirements but largely perform the same functions. Hydraulic machines are more precise and better for large clamping forces, but all-electric machines are much more efficient in terms of energy consumption. Literature suggests that all-electric machines can have energy savings between $60 \%$ and $70 \%$ compared to hydraulic [1]. For this reason, there has been a recent trend towards all-electric injection molding machines and some manufacturers have stopped building hydraulic machines altogether. In the United States, the amount of energy consumed by injection molding alone is greater than the whole electric 
production for some developed countries [8]. In the plastics industry, there is still room for improvement, especially in growing economies like India and China.

The plastics production stage is energy intensive and has large emissions. The main metric for injection molding is energy consumption. Material waste and cycle times can be reduced with a hot runner system, in which the runners are thermally controlled to keep the plastic from solidifying [8]. The key parameters that factor into energy consumption are pressure, temperature, cycle times, and mass flow rate. For this reason, the amount of energy consumed by an injection molding machine can vary greatly depending on the material being processed. Gupta et al. [2] describe a m ethodology for estimating the energy required to manufacture a part through injection molding so that appropriate changes could be made during the design stage. Golf balls are highly standardized products so the design cannot be changed much, but simulation can accurately estimate the materials used because of this standardization. Past literature has shown little emphasis on collecting accurate data to build simulation models [9]; this is perhaps because it is rare for companies to publicly release factory data. Note that the golf ball factory system discussed in the paper is built with some real-world data (literature) and estimated data (for purposes of simulation).

\section{Technical Approach}

The study aimed to define how best DES and Life Cycle Inventory (LCI) data, as part of LCA, could be combined to help analyze the utilization and processing of manufacturing unit processes. Figure 1 illustrates the technical approach. In manufacturing, a unit process is a single component part of the end-to-end manufacturing process that transforms raw materials into finished goods. Additionally, the study sought to determine the implications of such methods and evaluations to reduce the financial and environmental costs for energy intensive manufacturing processes. In building the model, the current LCI for injection molding was evaluated. The following what-if scenarios in a simplified golf ball factory using as close to real-world data as possible demonstrate DES and LCA's ability to facilitate decision-making and optimize energy intensive manufacturing processes such as injection molding.

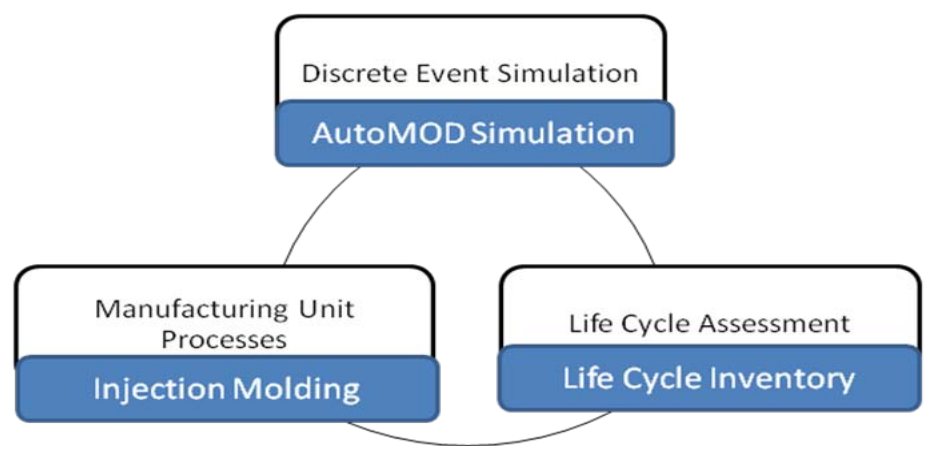

Figure 1. Technical approach 


\section{Case Study Scenario}

The simulated golf ball factory is composed of five steps: Injection Molding, Polishing, Painting, Coating, and Packaging. For the purposes of the DES simulation, Injection Molding is split into two steps: plasticizing and clamping. The ionomer resin cover material is melted in the barrel and injected around the rubber core of the ball, held by pins in the mold (See Appendix Figure 9). Once it is cooled, it is ejected and the seam and rough spots on the ball are removed by polishing. After the polishing is over, the ball receives two coats of paint and a final clear coat. The last step is packaging the balls in boxes before they are ready for transport. One load produces 16 golf balls.
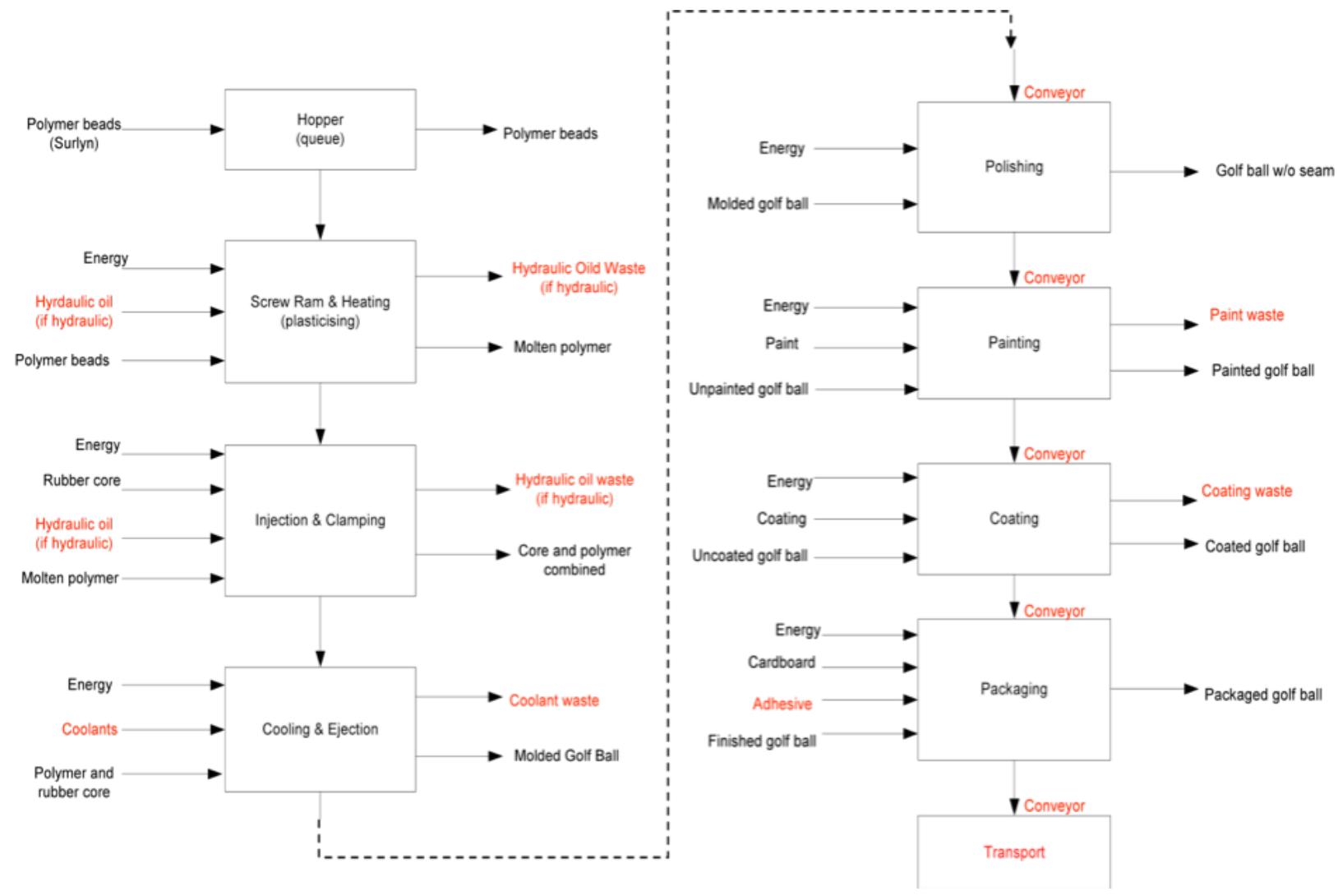

Figure 2. Input-Output diagram for golf ball manufacturing

The input-output diagram of the model (Figure 2) shows the unit processes in the model. Each of the steps requires some amount of energy, and most require a material input. The left half is devoted entirely to injection molding. The elements in red are not included in the model either due to unavailability of information or they were outside the scope of the project. There will also be energy losses in almost every step due to heat lost to the environment or inefficiencies within the machine. The drying and stamping procedures of golf ball manufacturing are omitted from this study. 


\subsection{Implementation}

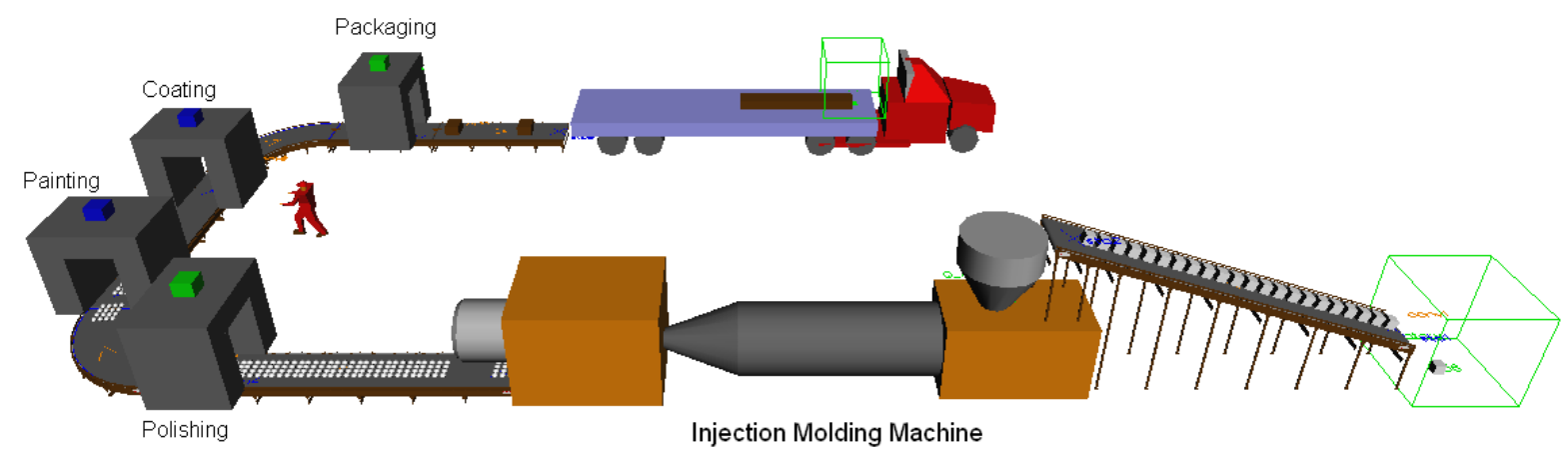

Figure 3. Simplified golf ball factory AutoMod simulation with one injection molding machine

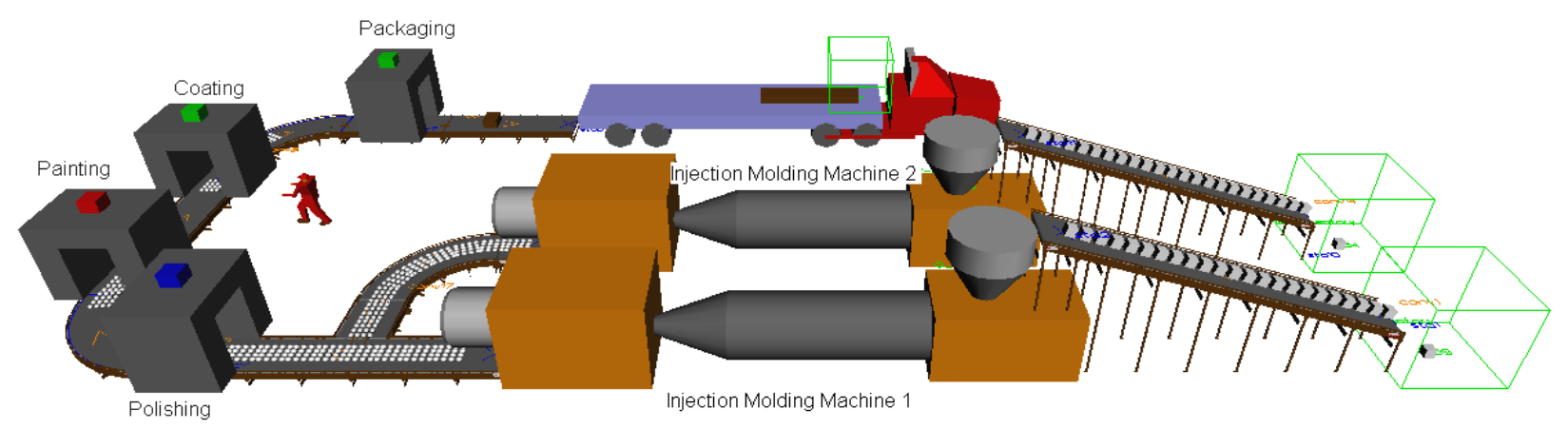

Figure 4. Golf ball factory simulation with injection molding machines in parallel

The case study scenario was implemented using AutoMod, a flexible 3-D simulation software that is ideal for manufacturing systems. AutoStat, a statistical analysis software for AutoMod, was used to run the trials. The above snapshots (Figures $3 \& 4$ ) show the set-up of the factory and how adding a second injection molding machine would affect it. Figure 3 also shows how the polishing machine becomes the bottleneck with the golf balls queuing up.

\subsection{Input Data}

The injection molding component of the simulation is largely based on real-world data from Thiriez's thesis on i njection molding [8]. Table 1 shows the injection molding data. For an unspecified type of Surlyn, DuPont's proprietary golf ball cover resin, the energy consumption and cycle times are given (Table 1). The two types of ionomer resins examined in the following simulation are Surlyn $9320 \mathrm{~W}$, which has the lower melting point of $70^{\circ} \mathrm{C}$ and therefore the shorter plasticizing cycle time, and Surlyn 8670 with a melting point of $100^{\circ} \mathrm{C}$ [10]. Polishing, painting, coating, and packaging machine data are estimated using similar equipment specifications. Material use is estimated through the standard requirements of golf balls. The material inputs are ionomer resin, rubber, paint, coating, and cardboard. Mean Time To Failure 
(MTTF) and Mean Time To Repair (MTTR) were chosen randomly depending on the process (see Table 2).

Table 1. Injection molding data on golf balls (From [8])

\begin{tabular}{|l|c|c|c|}
\hline $\begin{array}{l}\text { Variable Speed } \\
\text { Comparison }\end{array}$ & $\begin{array}{c}\text { Variable } \\
\text { Volume Pump }\end{array}$ & $\begin{array}{c}\text { Variable } \\
\text { Speed Drive } \\
\text { on Motor }\end{array}$ & Electric \\
\hline Machine size (ton) & 300 & 300 & 300 \\
\hline Shot Size (kg) & 0.25 & 0.25 & 0.25 \\
\hline Cycle Time (s) & 32.9 & 32.9 & 31.8 \\
\hline Throughput (kg/hr) & 27.57 & 27.57 & 28.53 \\
\hline Power Draw (kW) & 18.3 & 13.7 & 6.3 \\
\hline SEC (MJ/kg) & 2.39 & 1.79 & 0.80 \\
\hline Material & Surlyn & Surlyn & Surlyn \\
\hline Part Type & $\begin{array}{c}\text { Golf Ball } \\
\text { Covers }\end{array}$ & $\begin{array}{c}\text { Golf Ball } \\
\text { Covers }\end{array}$ & $\begin{array}{c}\text { Golf Ball } \\
\text { Covers }\end{array}$ \\
\hline
\end{tabular}

Table 2. Resource data used in the simulation

\begin{tabular}{|c|c|c|c|c|c|c|}
\hline \multirow[b]{2}{*}{ Resource } & \multirow[b]{2}{*}{$\begin{array}{l}\text { Injection Molding } \\
\text { (Plasticizing) }\end{array}$} & \multicolumn{3}{|c|}{ Unit Manufacturing Processes } & \multirow[b]{2}{*}{ Coating } & \multirow[b]{2}{*}{ Packaging } \\
\hline & & $\begin{array}{l}\text { Injection } \\
\text { Molding } \\
\text { (Clamping) }\end{array}$ & Polishing & Painting & & \\
\hline \multicolumn{7}{|l|}{ Processing Times (sec) } \\
\hline Cycle Time Distribution Type & N/A & triangular & triangular & triangular & triangular & triangular \\
\hline Lower Limit & N/A & 17 & 18 & 14 & 9 & 5 \\
\hline Mode & 10 & 20 & 20 & 17 & 10 & 7 \\
\hline Upper Limit & N/A & 23 & 22 & 20 & 11 & 9 \\
\hline \multicolumn{7}{|l|}{ Energy (kW) } \\
\hline Busy & 7.32 & 10.98 & 9 & 5.97 & 5.97 & 7.5 \\
\hline \multicolumn{7}{|l|}{ Failures } \\
\hline Distribution Type & exponential & exponential & exponential & exponential & exponential & exponential \\
\hline MTTF (min) & 13 & 15 & 5 & 7 & 8 & 10 \\
\hline MTTR (min) & 1 & 1 & 1 & 1 & 1 & 1 \\
\hline Material Consumed & Ionomerresin (cover) & Rubber(core) & N/A & Paint & Coating & Cardboard \\
\hline Amountperload & $0.2 \mathrm{~kg}$ & $0.4 \mathrm{~kg}$ & & $0.0151 \mathrm{~L}$ & $0.0076 \mathrm{~L}$ & $0.15 \mathrm{~m}^{\wedge} 2$ \\
\hline
\end{tabular}

The default settings (Table 2) are for the use of a hydraulic injection molding machine and an ionomer resin that requires a shorter cycle time for the plasticizing process. It is assumed that production of the ionomer resin and rubber core occurs before the simulation and that a hot runner system is used. Energy is based on usage time of the machine and material used is based on throughput. 


\subsection{Simulation Experiments}

In the AutoMod simulation model, four parameters were varied combinatorially. The parameters include: number of injection molding machines in parallel, the type of polymer used (affecting plasticizing time), the number of repairmen, and the type of injection molding machine (hydraulic, all-electric, or hybrid). Each scenario was run five times with a default time of one week, and then averaged. Figures 10 and 11 in the Appendix present the runtime snapshots from AutoMod simulation.

Note that the primary purpose of the simulation is to provide information for requirements of a golf ball factory in order to make its design more sustainable. The responses are in terms of materials, energy, $\mathrm{CO}_{2}$ emissions, and throughput. The $\mathrm{CO}_{2}$ emissions data is given by an $f$ factor for Maryland as described in Ameta et al. [11]. For Maryland, the value of $f$ is 0.620 metric tons/MWh. Energy Information Administration reports $\mathrm{CO}_{2}$ emissions in terms of metric tons. The factor $f$ is computed using the average energy mix available in each state in the USA and includes equivalent computations of impacts from emission of $\mathrm{CH}_{4}$ and $\mathrm{NO}_{\mathrm{x}}$ into $\mathrm{CO}_{2}$. With this information, decisions can be made that minimize energy usage while maximizing throughput.

\subsection{Results\& Discussions}

A number of conclusions can be drawn from the information provided by the simulation in terms of throughput, energy consumption, and materials. The following subsections discuss them specifically.

\subsubsection{Throughput}

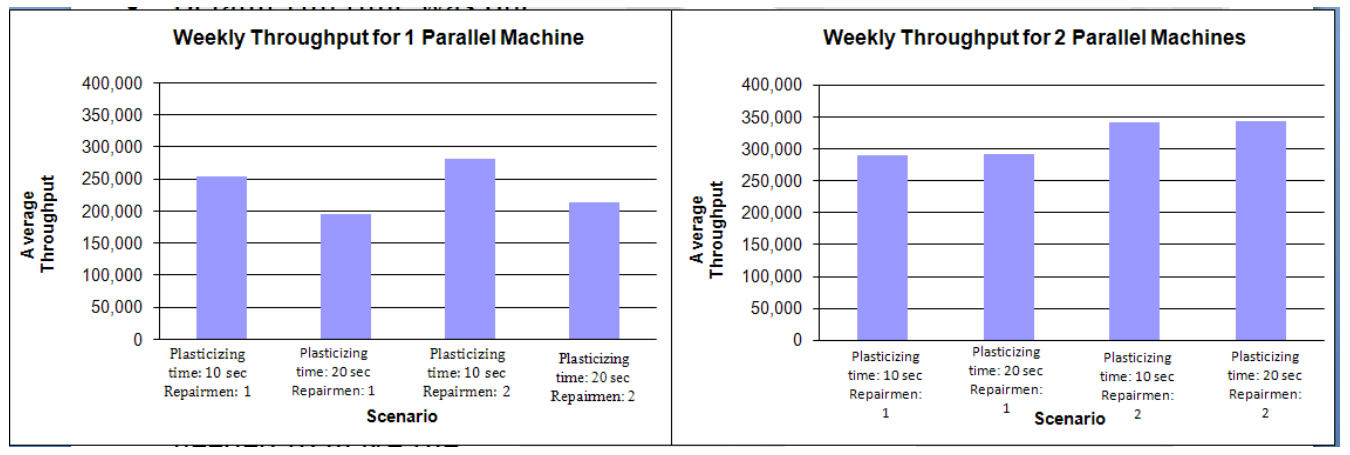

Figure 5. Weekly throughput

In both the single and parallel injection molding machine setups, the polishing machine was identified to be the utilization bottleneck. With one injection molding machine, adding a repairman had little effect (see Figure 5). H owever, both a second machine and a second repairman can increase the throughput to over 300,000 balls. In other words, a second repairman is needed to make the investment of another machine worthwhile. Plasticizing time had almost no effect on throughput for two machines, while using the higher melting point polymer for one machine compromises the throughput. 


\subsubsection{Energy Consumption}
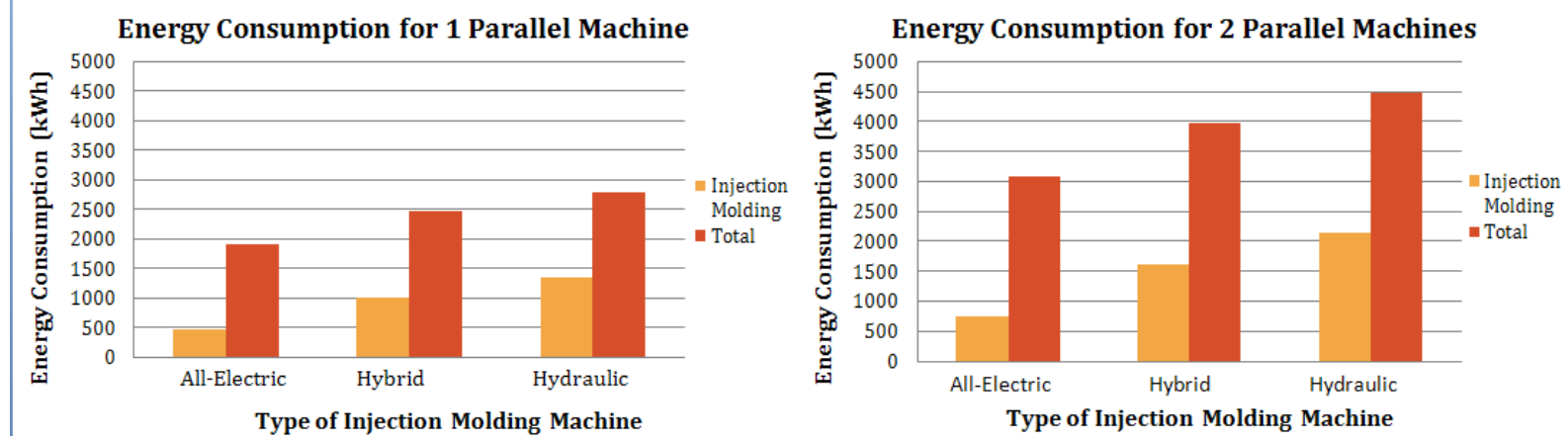

Figure 6. Energy consumption

The type of injection molding machine had a significant impact on energy consumption. For hydraulic machines, injection molding accounted for almost half of the total energy consumed, as opposed to about a quarter for all-electric machines. Injection molding was the most energyintensive step of the manufacturing process, unless the machine was all-electric. For the shorter plasticizing time and one repairman, the second machine was hardly used as shown by its small energy consumption (see Figure 6). In this case, type of machine would have an even greater effect on e nergy consumption because an idling hydraulic machine consumes much more electricity than an idling all-electric machine.

\subsubsection{Material Usage \& $\mathrm{CO}_{2}$ Emissions}

In this work the $\mathrm{CO}_{2}$ emissions were computed purely as a function of machine energy consumption. Changing from a hydraulic to an electric machine could cut down almost a third of the total $\mathrm{CO}_{2}$ emissions in every scenario (see Figure 7). However, these were extremely modest estimates due to the exclusion of HVAC, lighting, waste materials and transportation energy. Though output materials are included in the results (Table 3), a full LCA would include the environmental impacts of materials from extraction to disposal.

Total Annual $\mathrm{CO}_{2}$ Emmissions

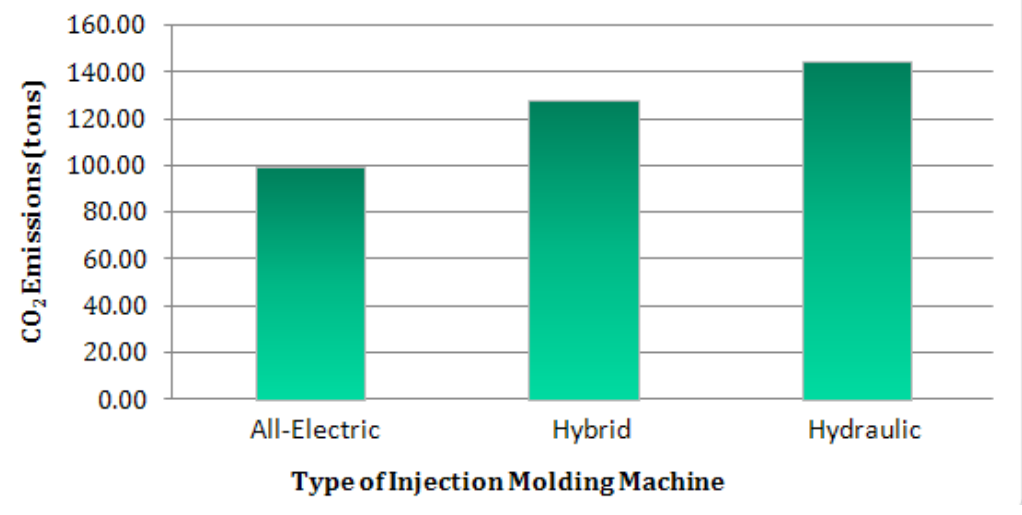

Figure 7. Material usage emissions 
Table 3. Material Usage Data

MaterialUsage
\begin{tabular}{|c|c|c|c|c|c|c|c|c|}
\hline \multicolumn{3}{|c|}{ Input parameters changed } & \multicolumn{3}{|c|}{ Output data from simulation } \\
\hline $\begin{array}{c}\text { \# of Injection } \\
\text { Molding } \\
\text { Machines }\end{array}$ & $\begin{array}{c}\text { IM Type/ } \\
\text { Power Draw (kM) }\end{array}$ & $\begin{array}{c}\text { Plasticizing } \\
\text { time(sec) }\end{array}$ & Repairmen & $\begin{array}{c}\text { Rubber } \\
(\mathbf{k g})\end{array}$ & $\begin{array}{c}\text { Polymer } \\
(\mathbf{k g})\end{array}$ & Paint (L) & Coating(L) & $\begin{array}{c}\text { Cardboard } \\
\left(\mathbf{m}^{\wedge} \mathbf{2}\right)\end{array}$ \\
\hline 1 & Electric (6.3) & 20 & 1 & 4879 & 2439.2 & 184.2 & 91.8 & 1829.2 \\
2 & Electric (6.3) & 20 & 2 & 8582 & 4290.8 & 324.4 & 162 & 3218 \\
\hline
\end{tabular}

Depending on the requirements of the factory, the simulation runs makes it clear what kind of trade-offs are worth the investment. For example, if the weekly throughput of the factory must be more than 300,000; a second injection molding machine must be invested in. In terms of throughput, investing in a second machine is probably only worth it if another repairman is hired as well. The percentage increase in throughput is greater than the percentage increase in injection molding energy consumption when adding a second machine, provided that there are two repairmen and the factory is processing the higher-melting-point ionomer. However, one aspect of machine processing that the simulation model does not capture is idle energy consumption. While all-electric injection molding machines consume significantly less electricity when idle, in hybrid and hydraulic machines especially, idle energy consumption can be quite high. Therefore, the disparity between the energy consumptions of the different types of machines and one or two injection molding machines would be even greater than what is shown in the data. If the annual $\mathrm{CO}_{2}$ emissions must be below 100 metric tons all-electric machines must be used.

Material waste is a large aspect of LCA and the simulation model gives estimates of material use by production yield. The extraction and processing of the raw materials consumes a significant amount of energy as does the transportation of those materials. Those aspects of the supply chain are beyond the scope of this study, but would increase the $\mathrm{CO}_{2}$ emissions drastically. In fact, the polymer production has the highest impact on the environment in the whole life cycle inventory of injection molding [8]. Additionally, hydraulic injection molding machines cause environmental problems in the form of hydraulic oil waste, which is not measured in this study. Coolant waste, which is generally water in a closed loop, is also not accounted for.

The environmental impact of the paint and coating depend on the volatility of the compounds used. The Environmental Protection Agency (EPA) regulates the use of volatile organic compounds (VOCs), which pose health risks as well as environmental concerns. Golf ball manufacturers can typically save money by using VOCs rather than less-toxic aqueous solvents. Water-based coatings are much harder to evaporate, requiring energy-intensive, expensive drying ovens [12]. Weighing these trade-offs is something that would require further investigation and a more in-depth factory simulation.

\section{Conclusion and Future Research}

The main purpose of the study was to illustrate the potential of incorporating LCA with the input data in discrete event simulation for manufacturing applications. Regulations on manufacturing 
waste and energy usage are becoming increasingly stringent, and companies are looking for ways to reduce their carbon footprint without sacrificing the quality and quantity of their products. By designing a discrete event simulation of a factory setting in tandem with sustainability metrics, companies can focus their resources more effectively. While renewable energy sources are going to be instrumental for a sustainable future, optimization of factories through simulation is an immediate answer to resource depletion.

This project was conducted as part of a Summer Undergraduate Research Fellowship (SURF) program at the National Institute of Standards and Technology (NIST). Owing to the duration of the project (3 months), there are several shortcomings with the design of this simulation which could be addressed in the future. The study could benefit from a systems approach to problem solving, where the focus is on the entire factory rather than injection molding in particular. The total energy statistic covers only the energy spent by the factory machines. The inclusion of energy used by HVAC and lighting systems, extraction, transportation, and processing of materials, conveyer energy, etc. would make the output data more applicable. The $\mathrm{CO}_{2}$ emissions by the simulated factory are likely a fraction of the emissions by a real-world factory. Future work could improve the accessibility of accurate real-world data, or programming sustainability metrics within the software itself, as demonstrated in the SIMTER project [13]. The lack of LCI data led to a general uncertainty with the results. Uncertainty quantification of the LCI datasets is a major work and must be done in the future to ensure reliable results. Finally, the study could also benefit from an analysis of the materials wasted during production and how much gets recycled.

\section{Disclaimer}

Mention of commercial products or services in this report does not imply approval or endorsement by NIST, nor does it imply that such products or services are necessarily the best available for the purpose.

\section{References}

[1] Kanungo, A., Swan, E. 2008. A 11-Electric Injection Molding Machines. In Proceedings from the Thirteenth Industrial Energy Technology Conference, New Orleans, LA. 6-9 May 2008.

[2] Gupta, S. K., Weissman, A., Ananthanarayanan, A., Sriram, R. 2010. A Systematic Methodology for Accurate Design-Stage Estimation of Energy Consumption for Injection Molded Parts. In Proceedings of the ASME 2010 International Design Engineering Technical Conferences \& Computers and Information in Engineering Conference, Montreal, Canada. 15-18 August 2010.

[3] Solding, P., Thollander. P. 2006. Increased Energy Efficiency in a Swedish Iron Foundry Through Use of Discrete Event Simulation. In Proceedings of the $2006 \mathrm{~W}$ inter 
Simulation Conference, eds. Perrone, L. F., Wieland, F. P., Liu J., Lawson, B. G., Nicol, D M., Fujimoto, R. M. Monterey, CA, USA.

[4] Östergren, K., Berlin, J., Johansson, B. Stahre, J., Tillman, A.M. 2007. A tool for productive and environmentally efficient food production management. European Conference of Chemical Engineering, Copenhagen, 16-20 September 2007.

[5] Johansson, B., Stahre, J., Berlin, J., Östergren, K., Sundstrom, B., Tillman, A.M. 2008. Discrete Event Simulation with Lifecycle Assessment data at a Juice Manufacturing System. In Proceedings of the $5^{\text {th }}$ FOODSIM Conference, University College Dublin, Ireland.

[6] Johansson, B., Mani, M., Skoogh, A., Leong, S. 2009. Discrete Event Simulation to Generate Requirements Specification for Sustainable Manufacturing Systems Design. In Proceedings of the $9^{\text {th }}$ Performance Metrics for Intelligent Systems workshop, Gaithersburg, MD. 21-23 September 2009.

[7] Mattis, J., Sheng, P., DiScipio, W., Leong, K. 1996. A Framework for Analyzing Energy Efficient Injection-Molding Die Design, Technical Report (CSM Report-96-09), California: University of California, Berkeley, 1996.

[8] Thiriez, A. 2006. An Environmental Analysis of Injection Molding, Masters Thesis at Massachusetts Institute of Technology, Cambridge, MA, USA.

[9] Massey, T., Wang, Q., 2007. The Development of a Discrete-Event Simulation Model to Aid the Design of Complex Manufacturing Systems. Engineering Letters 16.1 (2007). 19 Feb. 2008.

Web http://www.engineeringletters.com/issues_v16/issue_1/EL_16_1_20.pdf [Accessed July 16, 2010].

[10] Matweb [WWW]. [Cited 7.16.2010]. Available: http://www.matweb.com

[11] Ameta, G., Mani, M., Rachuri, S., Feng, S. C., Sriram, R. D. and Lyons, K.W. 2009 Carbon weight analysis for machining operation and allocation for redesign', International Journal of Sustainable Engineering,2009.

[12] U.S. Patent Application No. 12/336,728, Publication No. 20100151971 (published June 17, 2010) (Robert Wilson, applicant).

[13] Heilala, J., Saija, V., Tonteri, H., Montonen, J., Johansson, B., Stahre, J., Lind, S. 2008. Simlation-Based Sustainable Manufacturing System Design, In Proceedings of the 2008 Winter Simulation Conference, eds. Mason, S.J., Hill, R. R., Piscataway, NJ: Institute of Electrical and Electronics Engineers, Inc. 


\section{Appendix:}

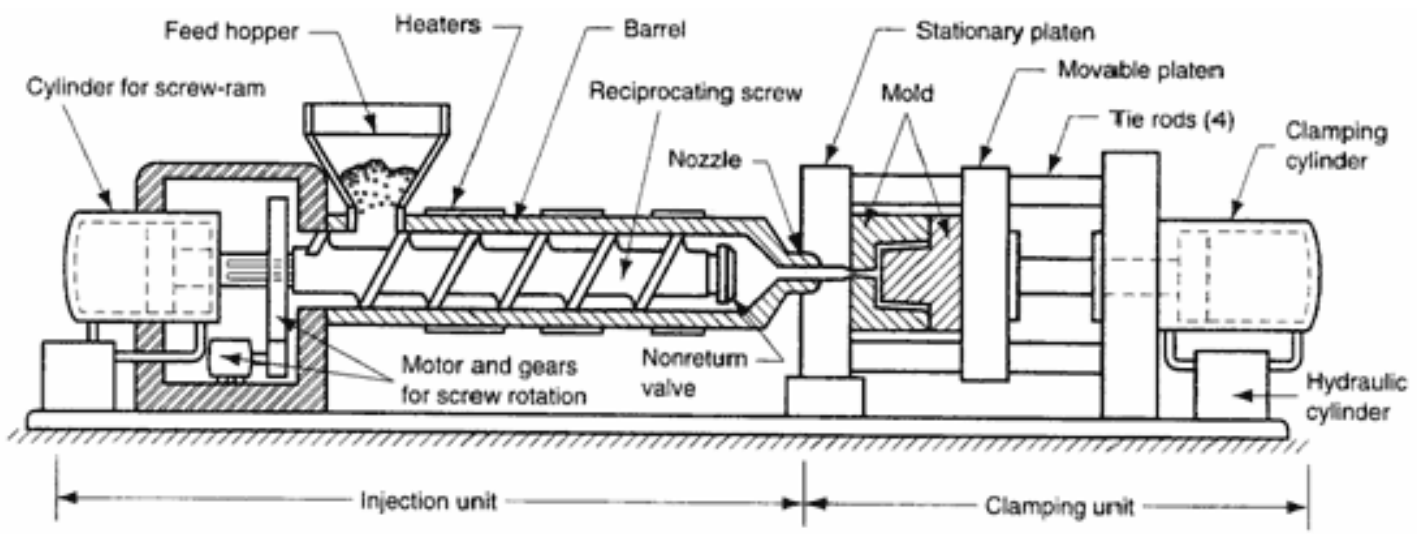

Figure 8. Injection molding machine (Source: http://plastics.inwiki.org/Injection_molding_machine)

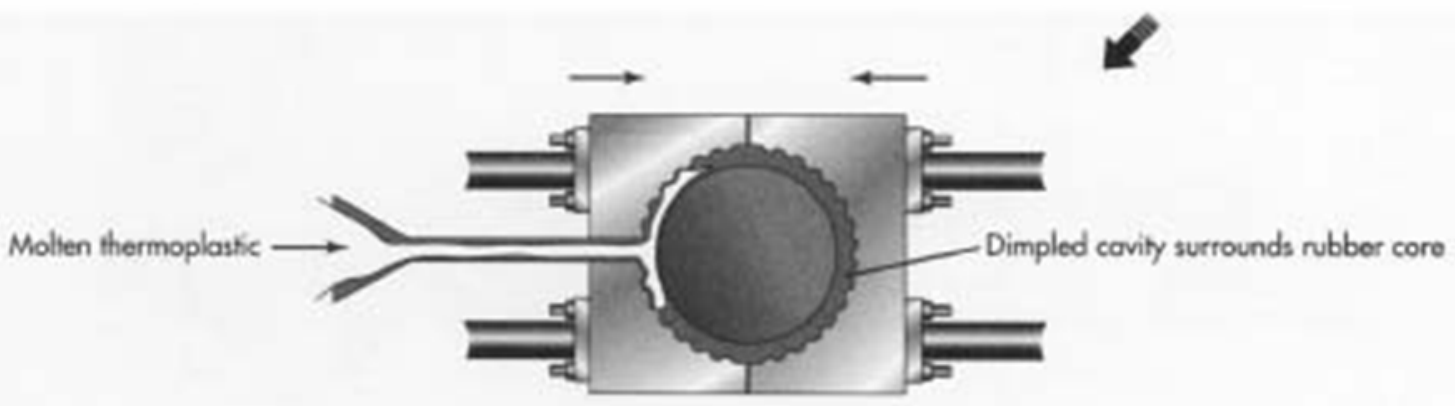

The cover is applied through injection or compression molding.

Figure 9. Injection molding of golf balls

(Source: madehow.com) 


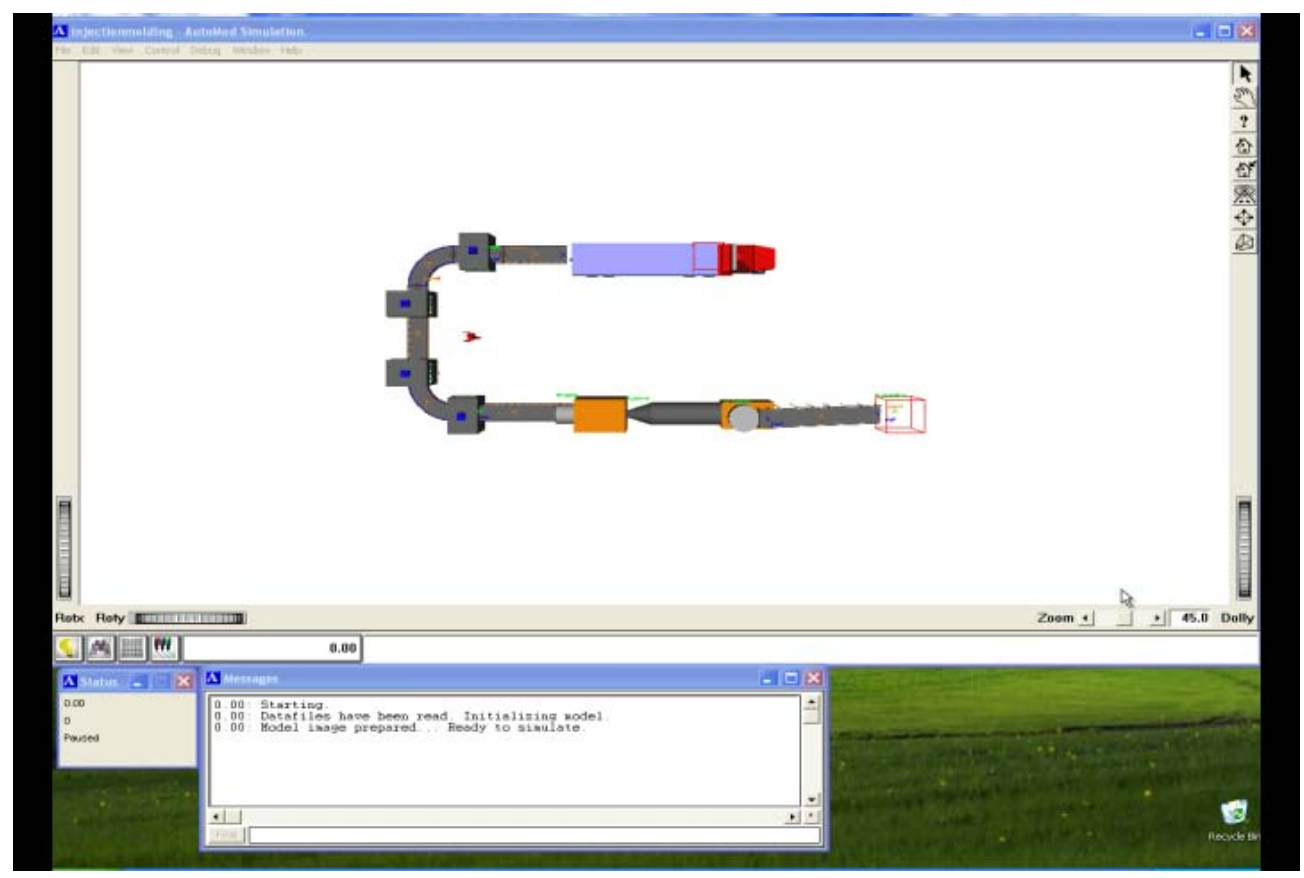

Figure 10. Runtime snapshot from AutoMod with one injection molding machine

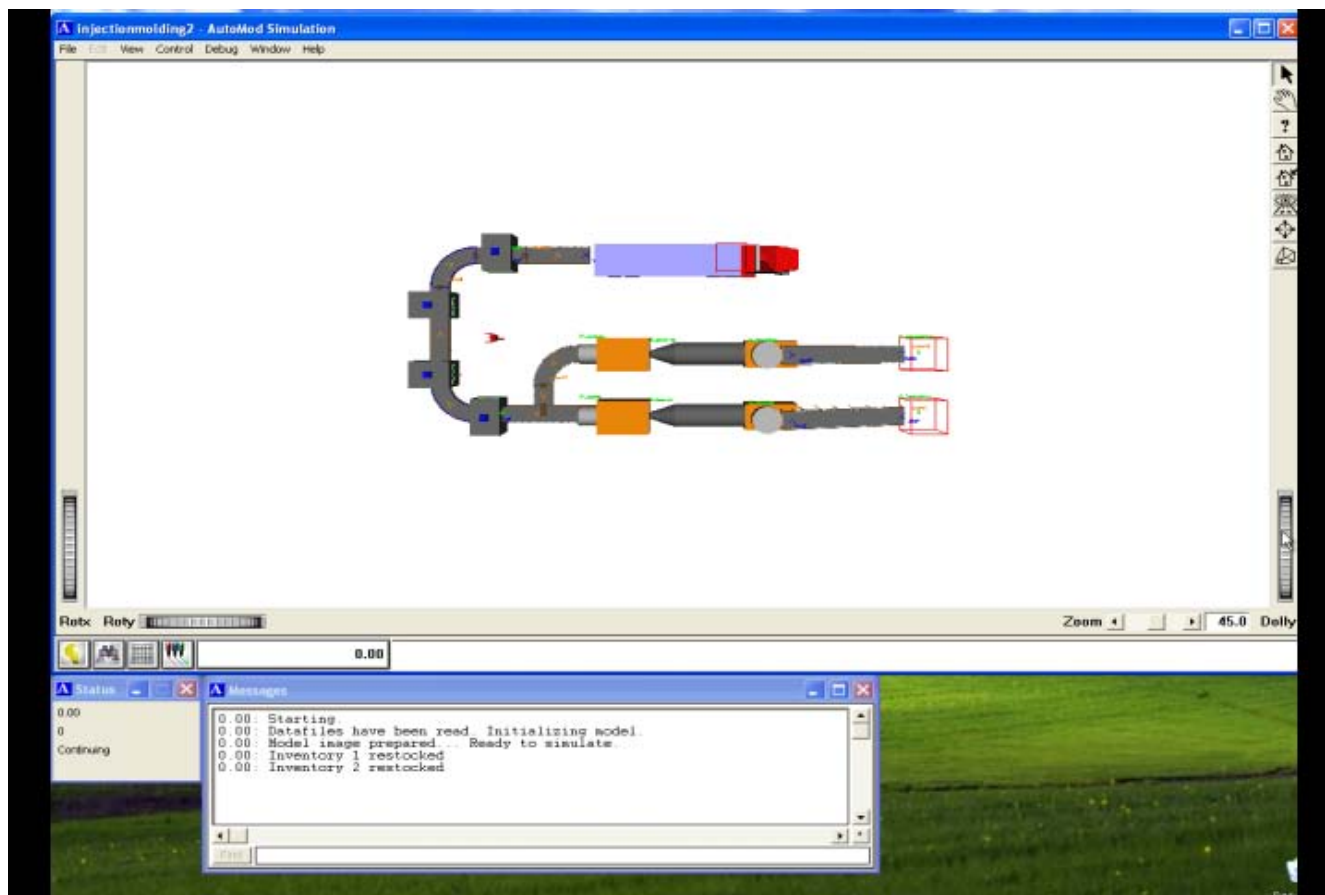

Figure 11. Runtime snapshot from AutoMod with two injection molding machines in parallel 